\title{
EOLÍ́TIOA Volume 33,2013 química \\ PROCESSAMENTO do ÓleO de GIRASSOL COMO ESTRATÉGIA PARA A PRODUÇÃo DE COSMÉTICOS ORGÂNICOS
}

\author{
Dayane Cristina de Moraes $^{1}$, Daniel de Paula ${ }^{1}$ \\ ${ }^{1}$ Universidade Estadual do Centro-Oeste/Departamento de Farmácia/Guarapuava, PR.
}

Formulações de cosméticos orgânicos não podem conter substâncias de origem sintéticas ou semi-sintéticas, e todas devem ter em sua composição matérias-primas de origem orgânica, obtidas segundo normas rígidas de extração, purificação e processamento. Dentre as alterações permitidas para a produção de matériasprimas orgânicas incluem-se as reações de hidrólise, esterificação, transesterificação, hidrogenação e saponificação. A saponificação é um processo de transformação de óleos e gorduras que consiste na reação de um triglicerídeo com um álcali formando um tensoativo. Os tensoativos têm aplicação em uma infinidade de produtos, podendo agir como agente emulsionante, detergente, espumante, condicionador, bactericida, solubilizante, entre outros. Um dos maiores desafios à produção de cosméticos orgânicos é a substituição de tensoativos sintéticos por substâncias de origem natural que apresentem propriedades funcionais tão aproveitáveis quanto os primeiros. Dessa forma, objetivou-se neste trabalho obter tensoativos orgânicos a partir do desenvolvimento de um processo de saponificação do óleo de girassol com aplicabilidade em larga escala. Utilizaram-se quatro diferentes bases para realizar a saponificação ( $\mathrm{NaOH}, \mathrm{KOH}$, TEA e AMP 95). Os tensoativos obtidos foram avaliados segundo características organolépticas, alcalinidade livre e capacidades espumógena, detergente e emulsionante, de acordo com métodos oficiais previamente descritos na literatura. Observou-se que as caraterísticas, bem como, a aplicação dos tensoativos obtidos na formulação de produtos cosméticos podem variar de acordo com a base utilizada no processo de saponificação, sendo que o tensoativo obtido a partir de $\mathrm{KOH}$ apresentou maior aplicabilidade, podendo ser usado na formulação de sabonetes líquidos e em barra e na produção de sistemas emulsionados.

Palavras-chave: cosméticos orgânicos, tensoativos, óleo de girassol.

\section{ABSTRACT}

Organic cosmetic formulations must not contain synthetic or semisynthetic substances. Otherwise, they must have materials of organic origin in their composition, which may be manufactured according to strict rules of extraction, purification and processing. The modifications allowed for the production of organic raw materials include hydrolysis, esterification, transesterification, hydrogenation, and saponification reactions. The saponification process consists of oils and fats transformation into surfactant by a reaction of triglycerides, present in oils, with an alkali. The surfactants are applied in several products and can act as emulsifiers, detergents, foaming agents, conditioners, bactericides and solubilizers. One of the biggest challenges to the development of organic cosmetics is to replace synthetic surfactants by natural excipients that have the same functional properties as the first ones. Thus, the aim of this work was to obtain organic surfactants by the saponification of sunflower oil using an up-scalable method. Four different alkalis were used to carry out the saponification reaction $(\mathrm{NaOH}, \mathrm{KOH}$, TEA and AMP-95). The final products were evaluated according to organoleptic properties, free alkalinity index and foaming, emulsifying and detergent capacity, based on official methods previously described in the literature. It was observed that the 
characteristics, as well as the applicability of surfactants on the formulation of organic cosmetics may vary according to the alkali used in the saponification process. The surfactant obtained from $\mathrm{KOH}$ presented the higher number of applications in organic cosmetics, which may be used in the formulation of liquid and bar soaps and emulsifying systems.

Keywords: organic cosmetics, surfactants, sunflower oil.

\section{INTRODUÇÃO}

O sistema orgânico de produção compreende um conjunto de métodos em que se adotam técnicas específicas, mediante a otimização do uso dos recursos naturais e socioeconômicos disponíveis e o respeito à integridade cultural das comunidades produtoras, tendo por objetivo (i) a sustentabilidade econômica e ecológica; (ii) a maximização dos benefícios sociais; (iii) a minimização da dependência de energia não-renovável, empregando, sempre que possível, métodos culturais, biológicos e mecânicos em contraposição ao uso de materiais sintéticos; (iv) a eliminação do uso de organismos geneticamente modificados e radiações ionizantes, em qualquer fase do processo de produção, processamento, armazenamento, distribuição e comercialização, e (v) a proteção do meio ambiente [1].

Fundamentando-se nessa premissa, surge o conceito de cosméticos orgânicos, cujo foco está concentrado no consumo consciente e saudável, diretamente relacionado ao bem-estar. Desse modo, os cosméticos associam-se intimamente à concepção da agricultura orgânica devido às matérias-primas neles contidas [2].

De modo geral, as formulações de cosméticos orgânicos não podem conter substâncias de origem $100 \%$ sintéticas ou semisintéticas, e todas devem ter em sua composição matérias-primas de origem orgânica, obtidas segundo normas rígidas de extração, purificação e processamento. O ideal é que as matérias-primas utilizadas nestes produtos sejam biodegradáveis e preservem ao máximo suas características originais. Estas podem sofrer determinadas modificações em sua estrutura, porém não as desqualificando por completo como naturais. Reações de hidrólise, esterificação, alquilação, condensação e saponificação são algumas das alterações permitidas para o processamento de matérias-primas orgânicas $[1,3]$.

Dentre as matérias-primas de origem vegetal, os óleos ocupam lugar de destaque sendo largamente utilizados na indústria cosmética. São constituídos principalmente por triglicerídeos com longas cadeias de hidrocarbonetos, pois são triésteres de glicerol comumente formados por moléculas de ácidos graxos. Os ácidos graxos são formados, geralmente, por ácidos carboxílicos contendo de 4 a 30 átomos de carbono em sua cadeia molecular, podendo ser saturados ou insaturados [4,5].

O Brasil é um dos maiores produtores mundiais de soja e possui grandes perspectivas para a produção de outras sementes. Dentre estas, destacam-se as sementes oleaginosas de girassol (Helianthus annuus L.), despontando como a cultura mais promissora do mundo, principalmente devido a sua grande adaptabilidade às diferentes condições edafo-climáticas [6].

A qualidade do óleo de girassol é determinada pela quantidade de ácidos graxos que o compõe, sendo o principal deles o ácido linoléico, representando mais de $60 \%$ do total de ácidos graxos presentes, seguido pelo ácido oléico, que constitui cerca de $23 \%$ da composição do óleo de girassol [7]. Ácidos graxos saturados (principalmente ácido palmítico e ácido esteárico) não chegam a mais de $15 \%$ do conteúdo de ácidos graxos [8]

Para adequá-lo a determinadas aplicações cosméticas, muitas vezes é necessário modificar as características do óleo de girassol. Nesse sentido, o setor industrial de óleos e gorduras tem desenvolvido diversos processos para manipular a composição das misturas de triglicerídeos [4,5]. A saponificação, por exemplo, é um processo de transformação de óleos e gorduras que consiste na reação de um ácido graxo ou triglicerídeo com um álcali formando um tensoativo $[9,10]$.

Os agentes tensoativos são moléculas anfifílicas exibindo um grupamento polar, denominado grupo hidrofílico solúvel em substâncias polares e um grupo hidrofóbico que possui afinidade por substâncias apolares, sendo chamado também de grupamento lipofílico $[8,9]$. Em relação ao caráter iônico de sua porção polar, os tensoativos são classificados em aniônicos, catiônicos, anfotéricos e não-iônicos [10,11]. O 
equilíbrio entre as características hidrofóbicas e hidrofílicas dos tensoativos regula sua aplicação como agentes umectantes, detergentes, emulsificantes, espumógenos, solubilizantes, condicionantes, espessantes e emolientes [10]. De modo geral, os tensoativos são utilizados em todos os sistemas dispersos empregados em formulações cosméticas, tais como suspensões, emulsões, géis, aerosóis, entre outros [12].

Um dos maiores desafios à produção de cosméticos orgânicos é a substituição de tensoativos sintéticos por substâncias de origem natural que apresentem propriedades funcionais tão aproveitáveis quanto os primeiros. Dessa forma, o uso de recursos naturais renováveis, tais como óleos de sementes, por exemplo, associado a um método de produção ecologicamente correto pode fornecer uma solução para esse desafio. Nesse contexto, o desenvolvimento de tensoativos com menor potencial de irritação, biodegradáveis e passíveis de serem incorporados em formulações orgânicas, é, portanto, de interesse geral. Assim, o presente trabalho objetivou otimizar a produção de tensoativos a partir de óleo de girassol, , empregando reação de saponificação, visualizando sua aplicação em cosméticos orgânicos.

\section{MATERIAL E MÉTODOS}

\section{Material}

Óleo de girassol (Cargil Agrícola, Brasil); ácido clorídrico PA (Labsynth, Brasil); álcool etílico absoluto (Dinâmica, Brasil); aminometilpropanol 95\% (AMP 95) (DEG, Brasil); carbonato de cálcio PA (Labsynth, Brasil); éter etílico PA (Dinâmica, Brasil); fenolftaleína PA (Dinâmica, Brasil); hidróxido de potássio PA (Quimibrás, Brasil); hidróxido de sódio PA (Dinâmica, Brasil); óleo mineral (Rioquímica, Brasil); Trietanolamina PA (Labsynth, Brasil).

\section{CARACTERIZAÇÃO DO ÓLEO DE GIRASSOL}

\section{Determinação do índice de acidez}

$O$ índice de acidez $\left(I_{A}\right)$ foi determinado de acordo com os ensaios físicos e físico-químicos para gorduras e óleos descritos na Farmacopeia Brasileira [13], e calculado pela equação (1):
(1)

$$
I_{A}=\frac{V \cdot N \cdot 56,1}{m}
$$

Onde $V$ é o volume de hidróxido de sódio gasto na titulação (em mililitros) $N$ refere-se à normalidade da solução e $m$ é a massa da amostra em gramas.

\section{Determinação do índice de saponificação}

$\mathrm{O}$ índice de saponificação $\left(\mathrm{I}_{\mathrm{S}}\right)$ foi determinado de acordo com método descrito na Farmacopéia Brasileira [13], e calculado com base na expressão (2). Foi efetuado um ensaio em branco nas mesmas condições, e o volume do titulante foi corrigido $\left(n_{1}-n_{2}\right)$.

$$
I_{S}=\frac{28,05\left(n_{1}-n_{2}\right)}{m}
$$

$m$ é a massa de amostra de óleo em gramas.

\section{PRODUÇÃO DOS TENSOATIVOS: REAÇÃO DE SAPONIFICAÇÃO}

Os tensoativos orgânicos foram obtidos através da reação de saponificação. Para viabilizar a reação, foram utilizados água destilada, óleo de girassol e as bases hidróxido de sódio $(\mathrm{NaOH})$, hidróxido de potássio $(\mathrm{KOH})$, trietanolamina (TEA) e amino metil propanol (AMP 95). Em todos os casos a base foi adicionada à água destilada (1:2), com agitação cautelosa até que ocorresse solubilização completa. Em seguida, a solução foi vertida sobre óleo ainda frio e, posteriormente, a mistura foi submetida ao banho termostatizado $\left(90^{\circ} \mathrm{C}-100^{\circ} \mathrm{C}\right)$, sob agitação mecânica a uma frequência de $250 \mathrm{rpm}$. Os tensoativos obtidos foram avaliados de acordo com suas características organolépticas, alcalinidade livre, capacidade espumógena, capacidade detergente e emulsionante.

\section{CARACTERIZAÇÃO DO TENSOATIVOS}

\section{Ensaios organolépticos}

As características organolépticas foram analisadas de acordo com BRASIL (2007) [14].

\section{Determinação do pH}

$\mathrm{O} \mathrm{pH}$ foi determinado utilizando $1,0 \%$ 
(p/p) da amostra de óleo saponificado diluído em água destilada com o auxílio de um pHmetro [14].

\section{Alcalinidade livre}

O teor de hidróxido livre presente na matéria saponificada foi estipulado, de acordo com BRASIL (2007) [14], após a realização da reação de hidrólise dos triacilgliceróis presentes no óleo de girassol para todas as amostras. A alcalinidade livre foi calculada com base na equação (3).

(3)

$$
\mathrm{C}=\frac{\mathrm{V} \cdot f c \cdot 0,004 \cdot 100}{m}
$$

Onde $V$ representa o volume do titulante gasto na amostra, em mililitros, $f c$ é o fator de correção do titulante e $m$ é a massa da amostra em gramas.

\section{Capacidade espumógena}

A partir da adaptação do método de "RossMiles", foram adicionados $100 \mathrm{ml}$ de solução de tensoativos em provetas graduadas de $250 \mathrm{ml}$, nas concentrações $0,1 \%$ e $1 \%$ com controle de temperatura $\left(25^{\circ} \mathrm{C}+/-2^{\circ} \mathrm{C}\right)$. As soluções foram agitadas manualmente por inversão durante 1 minuto. $\mathrm{O}$ volume de espuma formado foi medido em triplicata no tempo $0 ; 5 ; 10 ; 15$ e 30 minutos após a agitação. Foram preparadas soluções com água dura a $100 \mathrm{mM} \mathrm{CaCO}_{3}$ e destilada $[15,16]$.

\section{Capacidade detergente}

Com base no método descrito por Tamura et. al. (1999) [17], a capacidade de remoção de detritos gordurosos de superfícies hidrofóbicas foi avaliada em triplicata, empregando soluções de tensoativos na concentração de $1 \%$, em água destilada e dura $\left(100 \mathrm{mM} \mathrm{CaCO}_{3}\right)$.

\section{Capacidade emulsionante}

Em tubos de ensaio foram colocadas as proporções de óleo mineral/água: 9:1; 7:3; 5:5; 3:7 e 1:9. Acrescentaram-se tensoativos nas concentrações: $1 \% ; 5 \%$ e 10\%. Em seguida, os tubos de ensaio foram aquecidos em banho termostatizado até atingir uma temperatura entre $75-80^{\circ} \mathrm{C}$. Após, foram homogeneizados em agitador de tubos, em velocidade máxima, por 1 minuto, observando-se a formação de emulsão no tempo 0 e após 24 horas. O teste foi realizado em triplicata.

\section{RESULTADOS E DISCUSSÃO}

As características físico-químicas da matéria-prima utilizada para a obtenção de produtos tensoativos por si só, nem sempre fornecem conclusões que assegurem a destinação adequada dos mesmos para determinada formulação cosmética. A avaliação das propriedades tensoativas, tais como formação de espuma, detergência, emulsificação, em combinação com as características físico-químicas da substância é fundamental para determinar, de acordo com seu comportamento frente às análises, sua melhor aplicação cosmética.

\section{CARACTERIZAÇÃO DO ÓLEO DE GIRASSOL}

De acordo com a Farmacopeia Brasileira [13], o índice de acidez $\left(\mathrm{I}_{\mathrm{A}}\right)$ é definido como a massa de $\mathrm{NaOH}$, expressa em miligramas, necessária para a neutralização dos ácidos graxos livres presentes em um grama de amostra de óleo; e o índice de saponificação $\left(\mathrm{I}_{\mathrm{S}}\right)$ é o número de miligramas de $\mathrm{KOH}$ necessário para neutralizar os ácidos graxos resultantes da hidrólise de um grama da amostra. $\mathrm{O}$ índice de acidez obtido foi $0,08 \mathrm{~g}$ de ácido oléico/100g óleo, tal resultado é concordante com o Regulamento Técnico para Fixação de Identidade e Qualidade de Óleos e Gorduras Vegetais aprovado pela ANVISA [18]. $\mathrm{Na}$ análise do índice de saponificação, o valor médio obtido foi de $224 \mathrm{mg} \mathrm{KOH} / \mathrm{g}$, encontrandose próximo do limite estabelecido [18].

\section{PRODUÇÃO DOS TENSOATIVOS: REAÇÃO DE SAPONIFICAÇÃOO}

A hidrólise alcalina dos óleos é mais comumente conhecida como reação de saponificação. Os produtos resultantes são o glicerol e os sais alcalinos dos ácidos graxos, chamados de sabões [19]. O sabão natural representa o mais simples dos tensoativos aniônicos. A quase totalidade dos tensoativos utilizados em produtos cosméticos para cuidados pessoais, tais como, sabonetes em barra e xampus, contêm grupos aniônicos [10].

Para saponificar os ácidos graxos esterificados ao glicerol, pode-se utilizar $\mathrm{NaOH}$, $\mathrm{KOH}$, ou uma mistura destes. Também é 
possível o emprego de carbonatos de sódio e de potássio, amônia e bases orgânicas nitrogenadas, como as etanolaminas, por exemplo [20].

De acordo com Bancourt (1991) [21] e Azevedo et al.(1994) [22], há pelo menos três fatores que influenciam de maneira contundente o processo de saponificação de óleos: (i) Temperatura, esta tem um efeito dramático sobre a taxa de reação. $\mathrm{O}$ aumento da temperatura acelera a saponificação. Portanto, a otimização da temperatura de reação é sempre realizada em processos industriais, a fim de obter uma resposta rápida e satisfatória; (ii) Velocidade de agitação, este fator é muito importante para assegurar o contato entre os reagentes. Em processos contínuos, é essencial que ocorra a emulsificação destes e (iii) Concentração da base: considerada o fator limitante da reação. No início, a reação de saponificação é lenta em decorrência da presença de pouca quantidade de produto formado em solução. Com o aumento da concentração de sabão, a velocidade da reação cresce até que a maior parte do óleo seja consumida. A reação volta a ficar lenta na etapa final, devido à baixa concentração de óleo (20).

Para Cavitch (1997) [23], a velocidade da reação de saponificação está diretamente relacionada à intensidade de agitação, ao grau de saturação do óleo empregado, à força da solução alcalina, à percentagem de água utilizada, e eventualmente, à temperatura ao qual a reação é submetida.

Os resultados obtidos para as quatro bases hidrolíticas utilizadas nas reações de saponificação do óleo de girassol são apresentados na Tabela I. O tempo decorrido para a completa hidrólise do óleo de girassol com $\mathrm{KOH}$ foi superior ao tempo necessário para o término da reação com $\mathrm{NaOH}$, sendo $4 \mathrm{~h} 30$ minutos e $3 \mathrm{~h} 10$ minutos, respectivamente.

A diferença de tempo necessário para o término da reação com as diferentes bases pode ser explicada em termos de constante de basicidade (pKb), cujo valor para o $\mathrm{NaOH}$ é $0,2 \mathrm{e}$ 0,5 para o $\mathrm{KOH}$ [24]. De acordo com Corey (1995) [25], quanto maior for o valor de $\mathrm{pKb}$, menor é a ionização da espécie em solução aquosa, resultando em menor capacidade de atrair prótons para si, portanto, mais fraca é a base. O mesmo pode ser aplicado à TEA e AMP-95. Como pode ser constatado na Tabela I, não foi possível obter produto saponificado a partir destas bases. Ambas não emulsificaram o óleo de girassol, a mistura apresentou-se heterogênea depois de quatro horas de reação, sendo interrompida sem sucesso. A TEA e o AMP-95 são bases orgânicas nitrogenadas, que em virtude da presença de um par isolado de elétrons no átomo de $\mathrm{N}$, tem um poder muito menor de atrair prótons do que a dupla carga negativa do íon óxido característico de bases fortes. São, portanto, consideradas bases fracas quando comparadas ao $\mathrm{NaOH}$ e KOH [24].

Para viabilizar a reação se hidrólise do óleo de girassol com TEA e AMP-95, seria necessário a adição de um agente catalisador,

como o níquel, por exemplo [26,27], o que restringiria sua aplicação em formulações cosméticas orgânicas.

Como as reações de saponificação foram submetidas às mesmas condições de temperatura, agitação e proporção de base hidrolítica e, ainda assim apresentaram variações no tempo de obtenção do produto, admitimos que o tipo de base e a composição da matéria-prima empregada influenciam de maneira mais decisiva o tempo de reação do que os fatores acima citados.

Os tensoativos podem ser empregados de diversas formas em produtos cosméticos. Eles são selecionados de acordo com sua funcionalidade e capacidade de atuar como detergentes, emulsionantes e agentes formadores de espuma. Produtos de higiene pessoal incluem sabões, sabonetes em barra cremes dermatológicos, produtos de limpeza facial, incluindo soluções anti-sépticas, e emulsões [28, 29].

Para a produção de tensoativos naturais em larga escala, há três processos de saponificação comumente utilizados pelas indústrias: a frio, semi-aquecido e aquecido [30]. O processo frio é o mais elementar. Envolve a adição gradual de gordura em um recipiente contendo solução de álcali ( $\pm 32 \%$ em peso) para garantir a saponificação completa. A mistura é mantida sob agitação vigorosa por cerca de duas horas. O processo não inclui a remoção de impurezas ou separação da glicerina que é produzida [31]. O processo semi-aquecido ocorre em torno de 70 $90^{\circ} \mathrm{C}$ utilizando uma bobina de vapor quente para acelerar e completar a hidrólise do óleo. Neste método, a gordura e a solução alcalina são adicionadas ao mesmo tempo em um recipiente, a mistura é agitada e aquecida, mas não fervida. A massa saponificada é transferida para quadros, 
onde se solidifica. Este processo permite que a quantidade de álcali requerida para a completa saponificação seja ajustada antes de se obter o produto final. De modo geral, o rendimento é maior e o tempo de endurecimento do sabão bruto em quadros de resfriamento é reduzido. Essas vantagens, em articulação com os ciclos de produção mais curtos e custos razoáveis, tornam o processo semi-aquecido uma alternativa flexível. Este processo é frequentemente usado em escala industrial para a produção de sabonetes amplamente comercializados [31, 32]. O processo aquecido é o mais tradicional empregado para a fabricação de sabões. Neste método, a solução de álcali é adicionada ao óleo já aquecido em caldeira, acompanhada de agitação constante, seguindo-se os estágios de fervura, salga, lavagem, fervura para lavagem e sedimentação. $\mathrm{O}$ processo dura cerca de 6-8 horas [33,34]. É considerado o método mais eficaz, isso porque a partir deste pode-se produzir sabões e sabonetes mais puros, assim como subprodutos de glicerina [35].

\section{CARACTERIZAÇÃO DOS TENSOATIVOS}

Como pode ser constatado na Tabela I, as amostras saponificadas com $\mathrm{KOH}$ e $\mathrm{NaOH}$ apresentaram índices de alcalinidade livre de $0,56 \%$ e $0,2 \%$ respectivamente. Conforme a Legislação Brasileira [35], a concentração máxima de álcali livre, expressa em Óxido de Sódio $\left(\mathrm{Na}_{2} \mathrm{O}\right)$, permitida para produtos tensoativos deve ser de $1 \% \mathrm{p} / \mathrm{p}$. Os tensoativos orgânicos sintetizados mostram-se, portanto, de acordo com este critério.

A análise do $\mathrm{pH}$ das amostras apresentou os seguintes valores: 10,8 para tensoativo saponificado com $\mathrm{KOH}$ e 11,2 para o produto obtido com $\mathrm{NaOH}$ (Tabela I). O pH elevado dos tensoativos é produzido pela ionização das espécies alcalinas em solução aquosa (equação 4), gerando cátions metálicos $\left(\mathrm{Na}^{+}\right.$e $\left.\mathrm{K}^{+}\right)$e ânions hidróxidos $\left(\mathrm{OH}^{-}\right)$, o que faz com que o $\mathrm{pH}$ da água sofra elevação até cerca de 10 ou 11. Assim, O $\mathrm{pH}$ do tensoativo tende a crescer ao reter a quantidade residual de álcali durante a síntese [23, 35].

$$
\mathrm{MOH}(\mathrm{aq}) \longrightarrow \mathrm{M}^{+}+\mathrm{OH}^{-}
$$

De acordo com os autores Barbosa \& Silva (1995) [36] e Ananthapadmanabhan et. al. (2004) [37], tensoativos naturais invariavelmente apresentam $\mathrm{pH}$ alcalino superior a 9,5; enquanto que tensoativos sintéticos, são em sua maioria neutros ou ácidos (pH 7 ou menos). A alcalinidade é uma característica desejável quando se trata de produtos destinados à remoção de sujeiras, uma vez que o caráter básico da matéria saponificada é proporcional à neutralização e eliminação de detritos hidrofóbicos [36].

A basicidade de tensoativos naturais provêm de sua dissolução em água, que libera pequenas quantidades de ácidos graxos e espécies alcalinas. Em consequência, sabões naturais frequentemente exibem um $\mathrm{pH}$ mais elevado em comparação a tensoativos sintéticos. Este argumento tem sido explorado com o intuito de defender a aplicação de tensoativos sintéticos em formulações cosméticas, todavia, evidências recentes sugerem que tensoativos sintéticos podem penetrar em camadas mais profundas da pele e remover com mais facilidade as substâncias estabilizadoras de $\mathrm{pH}$ do estrato córneo do que o fazem tensoativos naturais [38].

$\mathrm{O}$ pH da superfície cutânea é ácido, com exceção de algumas áreas, nas quais valores fisiologicamente elevados prevalecem, tais como, axilas e regiões genitoanal e interdigital [39]. O fato é que o $\mathrm{pH}$ ácido da pele desempenha um papel fundamental na função de barreira desta, bem como regula a flora normal $[28,40]$. Porém, este valor pode ser influenciado por uma série de fatores endógenos (idade, secrções sebácea e sudorípara e etnia, por exemplo) e exógena (detergentes, cosméticos, sabões) [41].

$\mathrm{O}$ potencial irritante de um produto cosmético depende de vários fatores. A natureza do tensoativo é um dos determinantes principais. Os tensoativos mais agressivos são aqueles derivados de ácidos graxos com comprimentos de cadeia contendo entre 10 a 14 carbonos, predominantes na gordura de coco, comumente empregada na produção de sabonetes [42]. De acordo com Epstein (2005) [43], moléculas tensoativas compostas por cadeias C12 saturadas apresentam permeabilidade cutânea máxima e são capazes de catalisar o influxo de água (resultando irritação mais severa), em comparação a tensoativos de cadeias mais curtas (C8-C10) ou mais longas (C14, C16, ou C18). Assim, o óleo de girassol empregado para a síntese de tensoativos proposto no presente estudo, constituído 
essencialmente por ácido linoléico (C18:2), apresenta naturalmente menor potencial de irritação cutânea.

Em concordância com Cavitch (1997) [23], o objetivo da produção de tensoativos não é sintetizar um produto neutro, e sim manter o $\mathrm{pH}$ dentro de um limite de 5,5 a 10. Segundo a autora, um $\mathrm{pH} \mathrm{7,0}$ para um $\mathrm{pH} 10,0$ provoca pouca ou nenhuma alteração na fisiologia normal da pele.

Entretanto, Korting \& Braun-Falco (1996) [40], defendem que a formação da bi-camada lipídica, bem como a capacidade de retenção de água na superfície cutânea dependem do $\mathrm{pH}$ do meio. Por essa razão, é aconselhável à pessoas propensas a desenvolver pele seca a utilização de produtos de limpeza ácidos, e não há razão para acreditar que poderia ser desvantajoso ou potencialmente mais irritante do que produtos alcalinos ou neutros [44].

Frente a esta discussão, cabe ressaltar que existem alternativas para neutralizar a alcalinidade dos tensoativos, com o intuito de destiná-los tanto à formulações de produtos de limpeza quanto à formulações de cosméticos para higiene pessoal. Vários materiais têm sido recomendados para tal proposta, os mais comumente empregados são bicarbonato de sódio, ácido bórico, óleo de cacau, ácido esteárico, ácido cítrico e ácido oléico [45]. Estes podem ser incorporados à formulação durante ou após o processo de saponificação, em quantidades suficientes para obter o $\mathrm{pH}$ desejado, e todas essas substâncias são aprovadas para a incorporação em cosméticos orgânicos $[1,3]$.

\section{Características organolépticas}

As características organolépticas observadas são concordantes com as descritas na literatura (Tabela I). De acordo com Friedman \& Wolf (1996) [29], o álcali utilizado na síntese dos tensoativos influencia diretamente as características do produto final. Sais de sódio são conhecidos como sabões duros, sendo utilizados na fabricação de produtos de limpeza para uso doméstico, como sabões em barra e em pó. Os sais de potássio, ou sabões macios, têm maior solubilidade em água e são usados em sabonetes, cremes de barbear e sabonetes líquidos [19, 29]. A dureza dos sabões é também influenciada pela natureza dos ácidos, ou seja, a partir de gorduras saturadas obtém-se sabões mais sólidos do que a partir dos óleos insaturados [19].

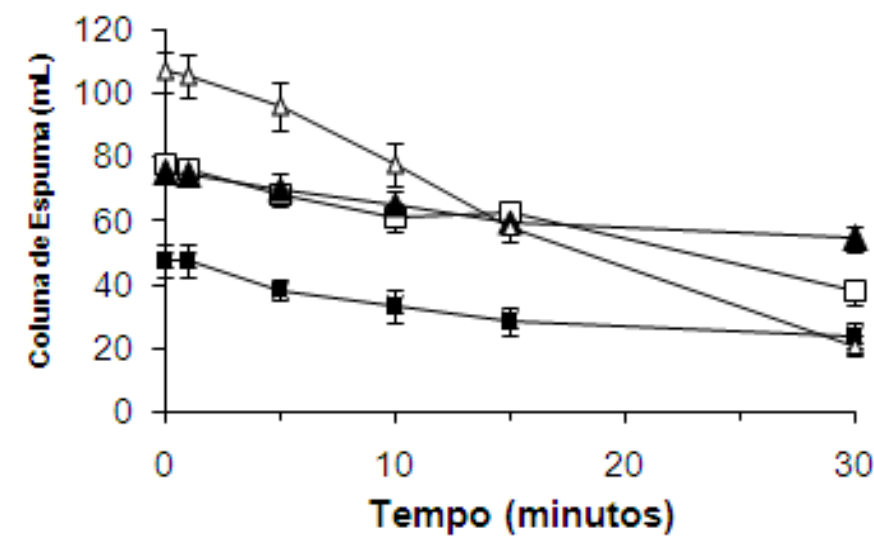

\section{Capacidade espumógena}

Os tensoativos desempenham papel fundamental na formação de espumas. Tais componentes apresentam característica anfifílica, fato que confere a estas moléculas a propriedade de adsorver-se em interfaces líquido-ar, causando a diminuição da tensão superficial do líquido estabilizando as bolhas de ar e impedindo sua rápida coalescência [46].

Em geral, tensoativos de alto poder espumógeno proporcionam filmes líquidos de drenagem lenta ao redor da bolha, os quais possuem grande quantidade de moléculas de tensoativo, conferindo a eles maior resistência. Este efeito é oposto para os tensoativos de baixo poder espumógeno [47].

De acordo com Rosen (1972) [48], a altura inicial de espuma está intimamente relacionada com a tensão superficial da solução tensoativa. Desse modo, quanto maior a força de cisalhamento, maior será a altura inicial da espuma, segundo o limite da solubilidade do tensoativo na solução. Assim, a análise da Figura 1, permite-nos constatar que ambos os tensoativos produzidos com $\mathrm{NaOH}$ e $\mathrm{KOH}$ são eficientes redutores de tensão superficial, pois apresentaram alta explosão de espuma, tanto em água dura (100 ppm $\mathrm{CaCO}_{3}$ ) como em água destilada. 


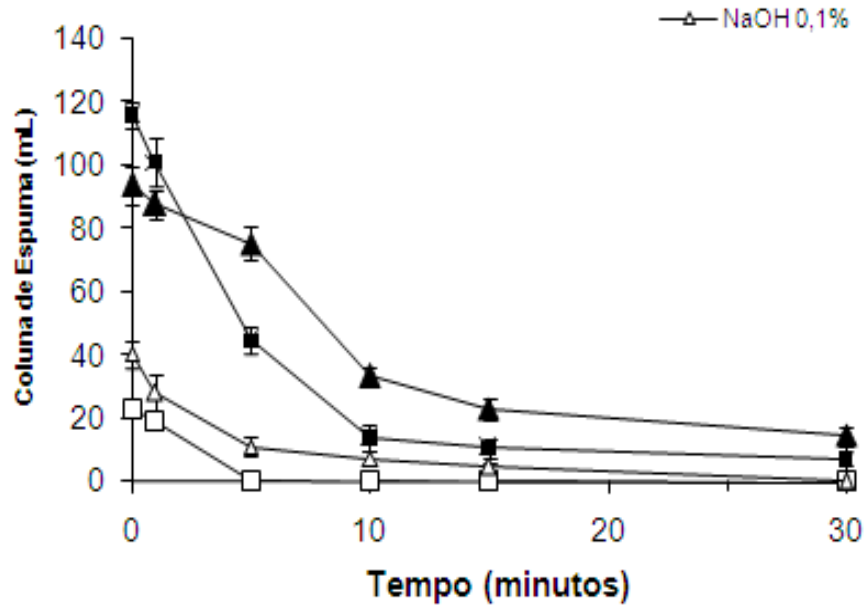

Figura 1: Capacidade espumógena do óleo de girassol saponificado com $\mathrm{NaOH}$ e KOH. (A) Água Destilada; (B) Água Dura. (100 mM CaCO3). $(\mathrm{n}=3)$.

Ainda na Figura 1, é possível notar que o menor volume de espuma em água destilada foi produzido pela solução a $0,1 \%$ do tensoativo obtido com $\mathrm{KOH}$. Em contrapartida, o tensoativo produzido com $\mathrm{NaOH}$, na concentração de $1,0 \%$ apresentou desempenho excelente, formando coluna de espuma superior a $100 \mathrm{~mL}$. Por outro lado, em solução de água dura, o tensoativo obtido a partir da hidrólise do óleo de girassol com $\mathrm{KOH}$, também na concentração de $1,0 \%$ produziu volume de espuma relativamente maior.

Para apresentar alta estabilidade de espuma o tensoativo deve possuir cadeia longa e linear, pois a baixa adsorção promoverá elasticidade e mobilidade. Contudo, como o aumento da cadeia também causa a diminuição da efetividade da molécula em reduzir a tensão superficial, assim há um pico máximo para o tamanho da cadeia, devendo este não ser superior a 18 carbonos $[48,49]$.

Em solução de água destilada, observa-se estabilidade relativamente boa de ambos os tensoativos. Tal estabilidade mostra-se independente da concentração dos tensoativos em solução (Figura 2).

Não obstante, baseando-se nos resultados obtidos, fica evidente que há diferenças significativas no que diz respeito à estabilidade da espuma quando considera-se o tipo de água em que esta foi formada. Em água dura, o tempo de manutenção da espuma foi extremamente curto, chegando a $100 \%$ de perda para todas as amostras. Isso deve-se ao fato de que em presença dos íons metálicos da água dura, o sal orgânico forma carboxilatos pouco solúveis, diminuindo sua concentração e seu poder espumógeno [19].

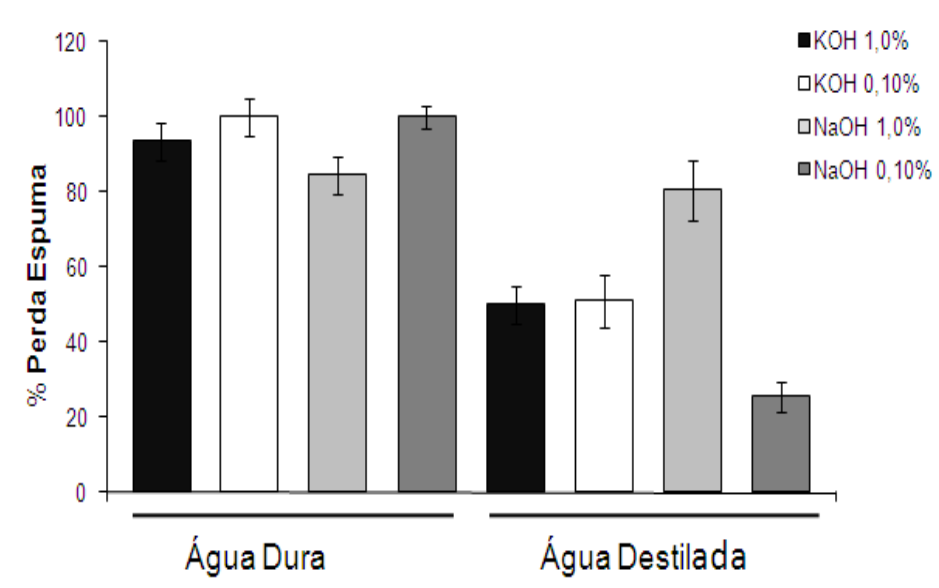

Figura 2: Percentagem residual de espuma em função do tempo $(\Delta \mathrm{T}) .(\mathrm{n}=3)$.

Apesar de não ser indicativa de eficácia de uma formulação cosmética, uma parcela significativa dos consumidores prefere utilizar produtos que apresentem ótimo desempenho espumógeno. Sabe-se hoje da dificuldade em produzir cosméticos orgânicos com alto poder espumógeno devido à falta de tensoativos que possam ser incorporados a estas formulações e que estejam de acordo com as diretrizes dos órgãos certificadores. Daí a importância de se avaliar o volume de espuma formado e sua estabilidade.

\section{Capacidade detergente}

Tensoativos são os constituintes principais de produtos cosméticos destinados à limpeza da pele, pois conferem a estes a capacidade de remover sujidades pouco solúveis em água (gordura, por exemplo), em razão de sua propriedade anfifílica [38]. Nem todos os tensoativos dão origem a detergentes eficientes. Para ser considerado um bom agente de limpeza, o tensoativo deve apresentar três características fundamentais: (i) poder molhante satisfatório; (ii) capacidade de remover a sujidade para dentro do líquido, afastando-a da superfície (iii) habilidade para solubilizar ou dispersar a sujidade e, uma vez removida evitar a sua redeposição sobre a superfície limpa [50, 51].

Para avaliação da detergência em laboratório são reportados numerosos métodos, 
mas não existe um padronizado e universalmente aceito que possua forte correlação com a prática de lavagem [52]. Basicamente, os ensaios para medir o poder de limpeza dos tensoativos fundamentam-se em sua capacidade de remover a gordura de superfícies sólidas [11]. Este é um processo não-espontâneos em que a adição de um tensoativo com propriedades detergentes reduz a quantidade de energia necessária para eliminar o depósito gorduroso [53].

As superfícies sólidas empregadas nos ensaios de detergência podem ser duras (placas metálicas ou de porcelana, plásticos de alta densidade, vidros); material têxtil (lã, algodão, fibras sintéticas), ou ainda, uma parte do corpo (pele, cabelos, dentes). O substrato hidrofóbico utilizado pode ter composição química e tamanhos de partículas variados [51].

Tamura et. al.,(1999) [17], avaliaram a performance de limpeza de soluções contendo sistemas combinados de tensoativos sintéticos, e concluiu que o sistema lauroilamidopropilbetaína (LAPB)/ lauroildietanolamina (LDT) apresentou sinergismo positivo na atividade detergente. Neste estudo, a autora preparou uma solução de 1,7\% destes tensoativos em água destilda $\left(25^{\circ} \mathrm{C}\right)$, na proporção 4:6 de LAPB/LDT. Foi relatada a remoção de aproximadamente $80 \%$ da gordura aderida à superfície sólida.

Sabe-se que o LAPB e o LDT são tensoativos sintéticos largamente empregados em produtos cosméticos por possuírem, individualmente, detergência satisfatória [17, 54]. Porém, o sinergismo entre uma mistura de tensoativos promove resultados muitas vezes melhores do que aqueles obtidos para a sustância pura, devido à formação de micelas mistas, com propriedades distintas e específicas. Por isso as formulações de cosméticos destinados à limpeza da pele, trazem frequentemente uma mistura de tensoativos, buscando atingir a melhor sinergia entre os componentes [55].

Os resultados apresentados na figura 3 demonstram que os tensoativos orgânicos produzidos possuem alta eficiência em relação à capacidade detergente, em especial o tensoativo obtido a partir da saponificação do óleo de girassol com $\mathrm{NaOH}$, fato observado principalmente quando estes foram avaliados em presença de água destilada.

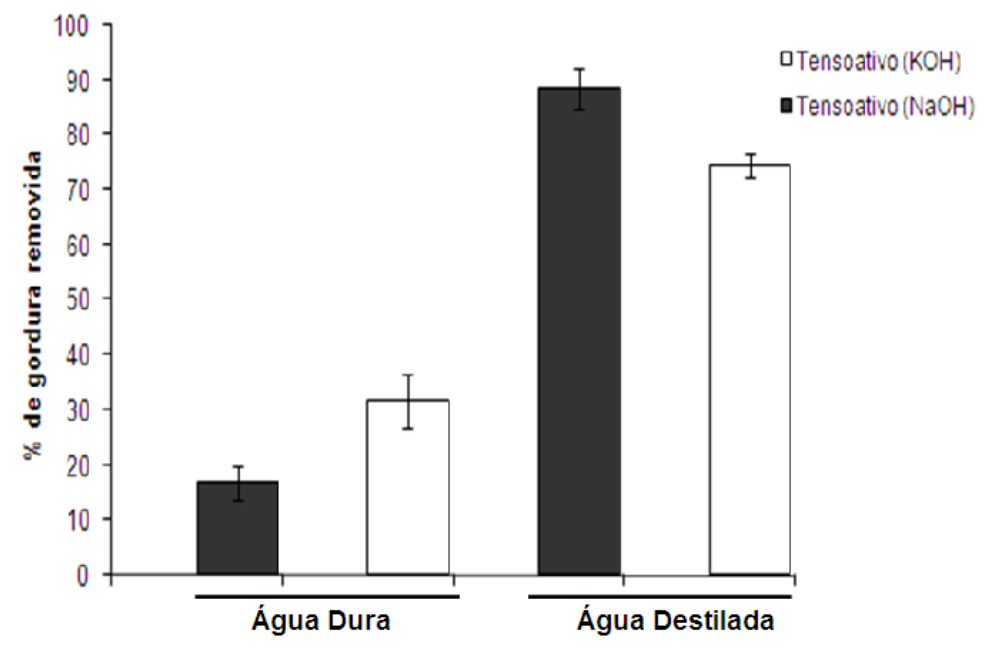

Figura 3: Capacidade detergente do óleo de girassol saponificado com $\mathrm{NaOH}$ e KOH. Concentração de tensoativo: $1 \%$; água dura (100 mM CaCO3); $\mathrm{n}=3$.

O tensoativo produzido a partir da hidrólise do óleo de girassol com $\mathrm{NaOH}$ apresentou um percentual de remoção de gordura de $88,43 \%$, seguido do tensoativo produzido com $\mathrm{KOH}$, que removeu $74,4 \%$ da gordura presente. Quando comparamos estes resultados aos dados apresentados por Tamura et. al., (1999) [17], podemos concluir que os tensoativos orgânicos produzidos são tão efetivos quanto os tensoativos sintéticos testados, visto que a solução de $1 \%$ de tensoativos orgânicos, na sua forma pura, ausente associações a outras substâncias, apresentou poder de detergência pouco inferior (base hidrolítica $\mathrm{KOH})$ e superior $(\mathrm{NaOH})$ aos tensoativos sintéticos, o que os torna viáveis para a incorporação em cosméticos orgânicos.

No entanto, em água dura $(100 \mathrm{mM}$ $\left.\mathrm{CaCO}_{3}\right)$, a presença de cátions polivalentes $\left(\mathrm{Ca}^{2+}\right)$ prejudicou de forma clara o processo de limpeza. Ao retomar-se a análise da Figura 4, é claramente perceptível que houve uma queda drástica no percentual de remoção de gordura pelos tensoativos produzidos a partir da hidrólise do óleo de girassol com $\mathrm{NaOH}$ e $\mathrm{KOH}$, representando $16,8 \%$ e $31,1 \%$ de remoção, respectivamente. Tal fenômeno pode ser explicado por pelo menos três fatores: (a) a adsorção de cátions polivalentes na camada negativa reduz os potenciais elétricos, dificultando assim a remoção da sujidade, facilitando a sua redeposição; (b) podem funcionar como ligações entre a camada carregada negativamente do tensoativo e a parcela carregada positivamente da sujidade, promovendo assim sua redeposição e, (c) em altas concentrações, os correspondentes sais de 
metais dos tensoativos aniônicos e de outros ânions (por exemplo, fosfatos, silicatos) podem precipitar sobre o substrato [55].

Quando a água é muito dura ou contém um alto nível de eletrólitos (como na água do mar), o desempenho detergente dos tensoativos orgânicos é seriamente reduzido, mas não totalmente inibido. Os agentes tensoativos sintéticos não apresentam essa desvantagem, e é por esta razão que eles têm sido usados na fabricação de produtos dermatológicos [29]. De fato, diversas formulações cosméticas contêm quantidade significativa de surfactantes sintéticos, porém, tem-se relatado com maior frequência casos de irritação cutânea e reações alérgicas com graus variados de gravidade associados à ação dos tensoativos sintéticos [51], o que nos leva a questionar até que ponto isso realmente representa uma vanatgem, ao trocarmos a segurança e integridade de nossa pele e saúde por um efeito detergente satisfatório em presença de íons metálicos.

A diferença no comportamento entre tensoativos sintéticos e orgânicos em água dura ou salgada está correlacionada com a solubilidade. Os últimos formam sais insolúveis e inativos na presença de magnésio e cálcio, contidos em água dura [29].

Como a dureza da água varia de acordo com a região geográfica, para diminuir esses efeitos, muitos métodos que auxiliam na eliminação destes cátions têm sido empregados. Em redes de tratamento de água, por exemplo, o abrandamento de águas duras é convencionalmente feito através de técnicas de filtração (osmose reversa e nanofiltração), métodos de troca iônica, abrandamento por precipitação química, com a utilização de agentes quelantes (trifosfatos e boratos) e precipitantes (carbonatos, silicatos e metassilicatos) e flotação $[55,56,57]$.

\section{Capacidade emulsionante}

O tensoativo orgânico produzido através da saponificação do óleo de girassol com $\mathrm{NaOH}$ foi capaz de formar emulsão satisfatória apenas quando aplicado na concentração máxima de $10 \%$, nas proporções óleo mineral/água 7:3 e 5:5 . O tensoativo produzido com $\mathrm{KOH}$, por sua vez, apresentou resultado bastante significativo ao formar emulsão nas proporções 5:5 e $3: 7$ a $1 \%$; 7:3 a 5\%; 7:3, 5:5 e 3:7 a 10\%. Todas as emulsões obtidas permaneceram estáveis durante o período de 24 horas. Em nosso laboratório foi realizado ensaio semelhante com tensoativos obtidos a partir do óleo de coco [58]. Neste, a formação de emulsão ocorreu somente nas proporções óleo coco:água $1: 9$ e $3: 7$ à $10 \%$ de tensoativo de óleo de coco saponificados com base $\mathrm{KOH}$ e na proporção 1:9 à $10 \%$ de tensoativo de óleo de coco hidrolizados com álcali $\mathrm{NaOH}$. Tal resultado expõe que a composição da matéria-prima utilizada na produção dos tensoativos influencia de maneira significativa as propriedades dos mesmos.

O óleo de coco é composto primordialmente por ácido láurico, representando mais de $40 \%$ do total de ácidos graxos presentes [59]. As gorduras láuricas são muito importantes na indústria cosmética pois são resistentes à oxidação não enzimática e ao contrário de outras gorduras saturadas, elas têm temperatura de fusão baixa e bem definida [60]. O ácido láurico, em combinação com KOH ou $\mathrm{NaOH}$ origina tensoativo extremamente eficazes na remoção de sujeiras, porém, emulsionantes não tão eficazes. Além disso, a composição do óleo de coco se assemelha com a do óleo de palma. Este último confere espumas cremosas e dureza ao sabão. Por este motivo, o óleo de palma é amplamente utilizado na fabricação de sabões, detergentes e outros tensioativos, sendo difícil encontrar uma formulação de sabonete que não inclua óleo de palma, ao passo que o principal ácido graxo constituinte do óleo de girassol é o ácido linoléico, muito empregado em cremes, loções e como emoliente para a reposição da umidade da pele [61]. Devido à elevada proporção de ácidos graxos insaturados constituintes do óleo de girassol, a obtenção de emulsão a partir de tensoativos derivados deste é grandemente facilitada. Esta propriedade pode ser explorada para inúmeros fins cosméticos.

Em formulações cosméticas orgânicas, têm-se empregado tensoativos obtidos a partir da reação de ácido esteárico natural ou animal com $\mathrm{NaOH}$ ou KOH, dando origem aos estearatos, utilizados para a obtenção de emulsões cosméticas, espumas para barbear, sabonetes e formulações moldadas [1,3].

Estudos realizados por Velasco et.al. (2008) [62] demonstraram que a lecitina de soja apresenta marcante capacidade de formação e estabilização de emulsãos quando adicionada a um sistema emulsionado, na proporção de 2,0\%. Lecitinas são lipídeos naturais que contêm fosfato 
em sua estrutura, daí muitas vezes, serem chamadas de lipídeos polares, característica que confere, a esta classe de substâncias, propriedades tensoativas. Nos últimos anos, a lecitina tem sido utilizada com sucesso na constituição de microemulsões atóxicas [73].

Frente a estes fatos, a adição de lecitina de soja, livre de modificcações genéticas, a uma emulsão obtida a partir dos tensoativos produzidos com óleo de girassol pode apresentar efeito sinérgico e facilitar a formação de emulsões mais estáveis com o intuito de favorecer a formulação de cosméticos orgânicos de alto valor sensorial e estético. 
Tabela I: Parâmetros reacionais e características dos produtos obtidos nas reações de saponificação.

\begin{tabular}{|c|c|c|c|c|c|c|}
\hline Base & $\begin{array}{c}\text { Tempo de } \\
\text { Reação }\end{array}$ & $\begin{array}{c}\text { Alcalinidade } \\
\text { Livre }\end{array}$ & pH & Cor & Odor & Consistência \\
\hline КОН & 4h30 minutos & $0,56 \%$ & 10,8 & $\begin{array}{c}\text { Amarelo } \\
\text { escuro }\end{array}$ & Imperceptível & Pastosa \\
\hline $\mathrm{NaOH}$ & 3h10 minutos & $0,2 \%$ & 11,2 & Branco & Característico de óleo & Sólida \\
\hline TEA & $\begin{array}{l}\text { Não ocorreu } \\
\text { reação }\end{array}$ & - & - & - & - & - \\
\hline AMP 95 & $\begin{array}{l}\text { Não ocorreu } \\
\text { reação }\end{array}$ & - & - & - & - & - \\
\hline
\end{tabular}




\section{CONSIDERAÇÕES FINAIS}

Um dos maiores desafios à produção de cosméticos orgânicos é a substituição de tensoativos sintéticos por substâncias de origem natural que apresentem características ótimas de detergência, formação de espuma e emulsão. Sendo assim, verifica-se a necessidade do desenvolvimento de técnicas compatíveis com os regimentos do sistema orgânico para o processamento de óleos vegetais vislumbrando a obtenção de tensoativos aplicáveis na área da cosmética orgânica de acordo com as diretrizes das instituições certificadoras, sinalizando o aproveitamento de recursos naturais e o desenvolvimento sustentável. Os resultados aqui apresentados qualificam a incorporação dos tensoativos obtidos a partir da saponificação do óleo de girassol em formulações cosméticas orgânicas. Porém, para garantir a eficácia e segurança do cosmético desenvolvido, são necessários testes de avaliação clínica, para determinar o potencial alergênico e irritante dos tensoativos produzidos, bem como o efeito do $\mathrm{pH}$ alcalino destes sobre a pele. Somando-se a isso, a adição dos tensoativos obtidos a outras matériasprimas orgânicas, tais como, alginato de sódio (doador de viscosidade), ácido cítrico (estabilizante), vitamina E (antioxidante) e óleos vegetais, poderá levar à formulação de emulsões de alto valor agregado para o mercado cosmético.

\section{REFERÊNCIA BIBLIOGRÁFICAS}

\section{[1] IBD - INSTITUTO BIODINÂMICO.}

Diretrizes para produtos de saúde e beleza orgânicos e naturais certificados e para matérias primas orgânicas e naturais certificadas. Disponível em: 〈www.ibd.com.br $>$. Acesso em 15 jun. 2011.

[2] M. B. M. Costa, Orgânicos e sustentabilidade: agregando valor aos produtos. In CONGRESSO DE AGRIBUSINESS, 9., 2007, Rio de Janeiro. Anais...p. 122.

[3] ECOCERT. Standards for ecological and organic cosmetics. Council of Europe; Committee of experts on cosmetic products, 2003.

[4] M. I. Gurr, J. L.Harwood, Lipid biochemistry: an introduction, Chapman \& Hall, London, 4 ed.,
1996, 243 p.

[5] A. Karleskind. Oils and Fats: manual. Lavoisier Publishing, Paris, 1 ed., 1996, 806 p.

[6] L. G. Santos, F. V. S. T. MELO, U. O. Souza, D. C. Primo, A. R. Santos, Enciclopédia Biosfera. 6 (11) (2010) 1.

[7] A. T. C. A. Chaves, Otimização do processo de produção de biodiesel etílico do óleo de girassol (Hellianthus annus) aplicando um delineamento composto central rotacional (DCCR). 2008. Dissertação (Mestrado em Química) - Universidade Federal da Paraíba, UFPB/CCE, Paraíba, 2008.

[8] K. Hill, Pure Appl. Chem. 72 (7) (2000) 1255.

[9] E. Jungermann, J. Am. Oil Chem. Soc. 56 (11) (1979) 827.

[10] J. J. Morelli, G. Szajer, J. Surfact. Deterg. 3 (4) (2000) 539.

[11] R. Wolf, D. Wolf, B. Tu“ Zu“ N, Y. Tu“ Zu“ N, Clin. Dermatol.19 (4) (2001) 393.

[12] L. D. Rhen, et. al. Surfactants in personal care products and decorative cosmetics, CRC Press, Taylor \& Francis Group, New York, 3 ed., 2007. 502 p.

[13] BRASIL. Agência Nacional de Vigilância Sanitária. Farmacopeia Brasileira,. ANVISA, Brasília, 5 ed, v. 1, 2010. 523 p.

[14] BRASIL. Agência Nacional de Vigilância Sanitária. Guia de Controle de Qualidade de Produtos Cosméticos. ANVISA, Brasília, 2 ed., 2008. 120 p.

[15] M. H. Amaral, J. Neves, A. Z. Oliveira, M. F. Bahia, J. Surfact. Deterg. 11 (4) (2008) 275.

[16] P. Goon, R. G. Bhirud, V. V. Kumar, Jour. Surfac. Deterg. 2 (4) (1999) 489.

[17] T. Tamura, T. Iihara, S. Nishida, S. Ohta, Jour. Surfac. Deterg. 2 (2) (1999) 207

[18] BRASIL. Resolução RDC ANVISA/MS nº 
482, de 23 de setembro de 1999. Regulamento Técnico para Fixação de Identidade e Qualidade de Óleos e Gorduras Vegetais. Diário Oficial [da República Federativa do Brasil], Brasília, DF, 23 set. 1999.

[19] V. K. L. Osorio, W. Oliveira, Quim. Nov. 24 (5) (2001) 700.

[20] J. A. Oliveira, Grau de saponificação de óleos vegetais na flotação seletiva de apatita de minério carbonatítico. 2005. Dissertação. (Mestrado em engenharia mineral) - Universidade Federal de Ouro Preto, MG, 2005.

[21] H. Bancourt. Saponification. In: Base documentaire scientifique et technique Techniques de lingénieur, 1991, J5810.

[22] J. C. S. Azevedo, W. S. Palheiros, P. R. G. Brandão, Estudo dos processos de saponificação do óleo de arroz e do óleo de rícino. 1994. Relatório. Escola de Engenharia da UFMG, Departamento de Engenharia de Minas, Belo Horizonte, 1994.

[23] S. M. Cavitch, The soapmaker's companion: a comprehensive guide with recipes, techniques \& know-how, Storey Publishing, North Adams, 2 ed., 1997, 281 p.

[24] N. L. Allinger, M. P. Cava, D. C. Jonhg, C. R. Johnson, N. A. Lebel, C. L. Stevens, Química Orgânica, LTC, Rio de Janeiro, 2 ed., 1976. 961 p.

[25] E. J. Corey, X.-M. Cheng, The Logic of Chemical Synthesis, John Wiley \& Sons, New York, 2 ed., 1995. 436 p.

[26] D. Lotayef, A. Shaheen, Oil and soap sector, Egypt, cleaning production opportunities. Disponível em: $<\mathrm{http}: / / \mathrm{www}$.eeaa,gov.eg. Acesso em: 14 jul. 2011.

[27] J. L. Slager, Surfactants: types and uses, Cuaderno FIRP, Merida, Universidad de Los Andes. Venezuela, 50 p. 2002.

[28] B. L. Kuehl, K. S. Fyfe, N. H. Shear, Skin Therapy Lett. 8 (3) (2003)1.

[29] M. Friedman, R. Wolf, Clin. Dermatol. 14 (1996) 7.
[30] B. Khalid, L. Liaquat, J. A. Khan, C. M. Ashraf, Jour. Chem. Soc. Park. 29 (1) (2007) 17.

[31] M. Donnez, CDI Guides: Technology Series, Context, Brusseles, 3rd ed.,1995.

[32] SSP pumps in the soap and detergent industry. Disponível em:< http//www.channelpumps.com>. Acesso em 28 mai. 2011.

[33] Commercial vs Traditioanal soaps. Disponível em: <http//www.30 someweeks.com/Know_Your_Soap.pdf $>$. Acesso em: 03 jul. 2011.

[34] E. F. R. O. Mota, Dossiê técnico: fabricação de produtos de higiene pessoal. Sociedade Brasileira de Respostas Técnicas. REDETEC. RJ, 2007.

[35] BRASIL. Resolução RDC ANVISA/MS $\mathrm{n}^{\circ} 13$, de 28 de fevereiro de 2007. Regulamento Técnico para Produtos de Limpeza e Afins. Diário Oficial [da República Federativa do Brasil], Brasília, DF, 28 fev. 2007.

[36] B. A. Barbosa, S. R. Silva, Química e Sociedade, Química Nova na Escola, 2 (1995) 3.

[37] K. B. Anathapadmanabhan, D. J. Moore, K. Subramanyan, M. Misra, F.Meyer, Dermatol. Ther. 17 (2004) 16.

[38] K. Ertel, Dermatol. Aspec. Cosmet. 18 (4) (2000) 561.

[39] M. H. Schmid, H. C. Korting, Dermatology. 191 (1995) 276.

[40] H. C. Korting, O. Braun-Falco, Clin. Dermatol. 14 (1996) 23.

[41] M. H. Schmid, H. C. Korting, Skin Pharmacol. Physiol. 19 (2006) 296.

[42] S. Abbas, J. W. Goldberg, M. Massaro, Dermatol. Ther. 17 (2004) 35.

[43] H. A. Epstein, Skin Med: Dermatology for the Clinician. 4 (3) (2005) 183. 
[45] W. H. Simmons, A. H. Appleton, A. H. The handbook of soap manufacture, Echo-Library Londres, 1 st ed., 2007.188 p.

[46] W. H. Venturelli, Estudo da atividade antiespumante de ésteres etílicos derivados de óleos vegetais. 2008. Dissertação (mestrado em Ciências, área: Química) - Universidade de São Paulo. Faculdade de Filosofia, Ciências e Letras de Ribeirão Preto. Ribeirão Preto, 2008.

[47] D. Sanctis, E. J. Palma, Tensoativos em xampus: um compromisso entre propriedades físico-químicas e atributos do consumidor. Artigo técnico. Oxiteno S. A Indústria e Comércio, 2001.

[48] M. J. Rosen, Jour. Amer. Oil Chem. Soci. 49 (1972) 294. In: E. F. LEITE, Sínteses e propriedades físico-químicas de novos tensoativos à base de oleaginosas brasileiras. 2010. Dissertação (Mestre em Ciências - Programa de Pós-Graduação em Engenharia Química. Área de Concentração: Novos Materiais e Química Fina) Universidade de São Paulo, Escola de Engenharia de Lorena, 2010.

[49] A. P. S. Pinheiro, J. M. Andrade, M. A. F. Melo, D. M. A. Melo, Influência da hidroxila da cadeia lipofílica na formação e estabilidade da espuma do tensoativo ricinoleato de sódio proveniente do óleo de mamona. In: CONGRESSO BRASILEIRO DA MAMONA, 2., 2006, Aracajú. Anais... Aracaju: Embrapa Algodão.

[50] T. F. Tadros, Applied surfactants: principles and applications, WILEY-VCH Verlag GmbH \& Co. KGaA, Weinheim 1 ed.,2005. 654 p.

[51] L. L. Schramm, E. N. Stasiukb, D. G. Marangoni, Annu. Rep. Prog. Chem., Sect. C. 99 (2003) 3.

[52] D. S. Sanctis, Formulando detergentes com baixa irratabilidade. Artigo técnico. Oxiteno S. A Indústria e Comércio, 2001. 13 p.

[53] N. K. Dimov, E. H. Ahmed, R. G. Alargova, P. A. Kralchevsky, P. Durbut, G. Broze, A. Mehreteabz, Jour. Colloid Interf. Sci. 224 (2000)
[54] G. U. Semblante, T. M. Chua, S. Chakraborty, Philippine Jour. Sci.138 (1) (2009) 49.

[55] E. F. Leite, Sínteses e propriedades físicoquímicas de novos tensoativos à base de oleaginosas brasileiras. 2010. Dissertação (Mestre em Ciências - Programa de Pós-Graduação em Engenharia Química. Área de Concentração: Novos Materiais e Química Fina) - Universidade de São Paulo, Escola de Engenharia de Lorena, 2010 .

[56] R. D. R. Silva, R. T. Rodrigues, J. Rubio, Remoção de dureza da água por precipitação dos íons $\mathrm{Ca}^{+2}$ e $\mathrm{Mg}_{+2}$ e flotação por ar dissolvido processo P-FAP. In: CONGRESSO BRASILEIRO DE ENGENHARIA QUÍMICA, 18., 2010, Foz do Iguaçu. Anais...p. 407.

[57] Y. Yu, J. Zhao, A. E. Bayly, Chinese Jour. Chem. Eng. 16 (4) (2008) 517.

[58] F. Zanette, D. de. Paula, Cosméticos orgânicos: produção de tensoativos à base de óleo de coco. In: ENCONTRO ANUAL DE INICIAÇÃO CIENTÍFICA, 19., 2010, Guarapuava. Resumo.

[59] D. K. Bhattacharyya, B. Chaterjee, Jour. Amer. Oil Chem. Soc. 61 (2) (1984) 417.

[60] G. C. Machado, J. B. P. Chaves, R. Antoniassi, Ceres. 53 (308) (2006) 463.

[61] M. Athar, S. M. Nasir, African Jour. Biotech. 4 (1) (2005) 36.

[62] M. V. R. Velasco, C. P. M. Maciel, F. D. Sarruf, C. A. S. O. Pinto, V. O. Consiglieri, T. M. Kaneko, A. R. Baby, Rev. Ciênc. Farm. Básica Apl. 29 (2) (2008) 179.

[63] M. F. T. Reis, Micelas reversas formadas por surfactante/solvente orgânico/água: estudotermodinâmico e aplicação para extração de proteínas da semente de jaca. 2010. Dissertação (Mestrado em Engenharia de Alimentos) Universidade Estadual do Sudoeste da Bahia, Itapetininga, 2010. 